\title{
Stress among Medical and Dental Students: A Global Issue
}

\author{
Dr. Aditya Jain ${ }^{1}$, Ramta Bansal ${ }^{2}$ \\ ${ }^{l}$ Assistant professor, Department Of Physiology Giansagar Medical College Banur, Distt Patiala( Punjab), \\ India \\ ${ }^{2}$ M.D.S. (Conservative Dentistry and Endodontics,) Patiala (Punjab), India
}

\begin{abstract}
The practice of medical and dental profession has long been associated with high levels of occupational stress. The stress of professional training can be a motivator for some, for others it can have serious consequences. By identifying stressors affecting students, necessary modifications can be made to improve the quality of life of dental and medical students. This article reviews the sources, impacts and solutions of stress among dental and medical students.
\end{abstract}

Keywords: Burnout, Dental Students, Education, Medical Student, Stress

\section{Introduction:}

Medical and Dental schools are known to be highly demanding and stressful learning environments. Stress is defined as "pressure or worry caused by problems in somebody's life" [1]. Stress is a matter of perception, because not all are equally affected. Stress is not specific for medical $\&$ dental students. Stress is a global issue as it is reported all over the world. All students in other professional fields also have academic pressures but not much is written about them. The relationship of stress and medical \& dental education is hyped because the personality of medical or dental students suggests that they are highly motivated, action oriented achievers, securing high grades prior to admission and we expect them not to be affected by stress or being incapable of handling it. High levels of stress and prolonged stress exposure may precipitate burnout, a term that describes the experience of long-term work-related exhaustion and diminished interest [2]. Several studies have shown stress encountered during dental education is more pronounced than during medical education [3]. Hermanson (1972) reported emotional illness ranked third among illnesses in dentists [4] and Cooper et al (1987) reported the dental profession is the most stressful of all health professions [5].

\section{Sources Of Stress}

The Garbee et al. Survey [6] recognized six categories of potential stressors causal categories for dental students: academic performance, faculty relations, patient and clinic responsibilities, personal life issues, professional identity, and financial obligations. For the purpose of making a clear understanding, stresses of both medical and dental students, are presented under these headings

\subsection{Stress due to academic performance:}

Kumar et al (2009) reported the most important source of stress among Indian dental students was the academic component of the course, especially in regard to examinations and grading [7]. For the preclinical students (first and second year students) examinations, grades and fear of failing a course or year are the greatest causes of stress because students have to focus on the completion of preclinical laboratory projects in addition to successful performance in demanding basic medical and dental sciences subjects which require a lot of study. Senior students, on the other hand, generally experience stress related to difficulties in meeting clinical requirements before being allowed to sit for examination. Heavy workload pressures result in a fear of failure due to concerns about falling behind in course requirements [8].

Studies of medical students have reported competitive pressures to achieve good grades in didactic examinations and clinical practice evaluations [9]. Other studies noted heavy workload and long hours during professional training as highly stressful experiences [10].

\subsection{Student Relationships with Faculty as a Potential Stressor}

Dental students reported high levels of stress due to unjustified criticism of their faculty on preclinical and clinical exercises. Sanders and Lushington found that students with higher levels of stress related to their relationships with faculty members tended to have lower grades in tests of clinical competence and basic understanding [11].

Medical students reported that they found few faculty members who were willing to serve as mentors. Holm and Aspergen reported that medical students who utilized both scientific and humanistic techniques were 
often criticized as not being as professionally competent as their colleagues who relied exclusively on an impersonal, scientific approach to managing patients[12].

\subsection{Patient and Clinical Responsibilities as a Potential Stressor}

Pau and Croucher conducted a study of British dental students and found that third- and fourth-year students had higher levels of stress than preclinical students [13]. The most common stressors included patients arriving late or not showing up for appointments, needing to find one's own patients and difficulty finding suitable patients.

The effects of chronic stress in medical school training have been reported. Students complain about their inability to empathize with their patients' anxiety in coping with their illnesses. Spencer concluded that the often-reported decline in medical empathy among medical students is due to transient social relationships, hurried and fragmented relationships with patients, and avoidance of intimacy during medical training [14].

\subsection{Personal Life Issues}

Acharya reported that Indian dental students were often stressed by the fear of facing their parents after failing academically [15]. Researchers in both dental and medical education have reported student frustration due to loss of opportunities for social and recreational activities and inadequate amount of time for rest and relaxation. Other personal life issues included being forced to postpone marriage or commitments, conflicts with partners over career decisions and discrimination against female dental students.

\subsection{Professional identity:}

Both dental and medical students suffer from a lack of confidence and uncertainty about their own abilities. Stress is due to a perceived lack of competence in being able to treat patients. Stress associated with residency choice is particularly high. Medical students are required to do a residency, whereas doing so is optional for dental students. There is a real fear of making a wrong decision and not entering the residency that is best for them. Additionally, competition for residency and postdoctoral programs is stress booster, as only the high rankers in entrance tests get enrolled to the most desirable programs.

\subsection{Financial obligations}

Increasing costs of a professional education is a very significant stressor for both medical and dental students. Along with this increasingly uncertain earning potential, has raised concerns about their long-term financial security among both medical and dental students.

\section{Impact:}

Stress can have detrimental effects on dental and medical students; it has been associated with physical symptoms, psychological distress, emotional exhaustion and burnout [16]. Physical consequences of stress are fatigue/tiredness, mood alteration, effect on performance, headaches, sleep disturbance, stomach disturbances, experiencing flu/common cold and development of oral ulcers. Psychological distress manifests showing higher levels of depression, obsessive-compulsive disorders, and interpersonal sensitivity than age-matched norms. To relieve these stresses students adopt leading stress reduction techniques that include reading magazines or books, Praying/spiritual activity, Meditation, Listening to music/playing a musical instrument, Shopping/window shopping, Watching movies at home or at the cinema, Smoking cigarettes, Drinking alcohol, Sleeping, develop strong interpersonal relationships i.e Spouse/girlfriend/boyfriend, talking to Friends, Family, Lecturers/mentors/academic advisors or seek Professional help: doctor, psychiatrist, counsellor.

\section{Solutions:}

It is important for dental and medical schools to identify stress levels among its students and create a student-friendly, less stressful working environment for their education. Although stress cannot be eliminated, appropriate measures can be undertaken to alter the students' maladaptive perceptions and reactions to those events. Students wishing to enrol in this field should be exposed to the nature of the profession and the study environment prior to applying to this program. This can be done by allowing potential medical and dental students to follow along at a government hospital. We also recommend an entrance interview to evaluate the candidate's interest and suitability for the course. Medical \& Dental schools should collaborate with educational experts in designing and developing a curriculum structure which is more student-orientated, aimed at enhancing the students' psychological well-being whilst maintaining a focus on academic and clinical performance and producing graduates with a positive professional attitude [17]. 


\section{Conclusion:}

High levels of stress and burnout have been documented among dental and medical students. Although some of the sources of stress are inherent in professional education due to diverse nature of educational stream and their settings but all the medical and dental institutes should identify and address potential sources of stress among their students, thus promoting the educational and professional well being of medical and dental students.

\section{References:}

[1] Hornby AS. Oxford advanced learner's dictionary. Oxford: Oxford University Press, 2010, 1477.

[2] Maslach C, Jackson SE. The measurement of experienced burnout. J Organ Behav, 2,1983, 99-113.

[3] Murphy RJ, Gray SA, Sterling G, Reeves K, DuCette J. A comparative study of professional student stress. J Dent Educ, 73, 2009, 328-37.

[4] Hermansonn PC. Dentistry : a harzadous profession. Dent Stud, 50, 1972, 60-1.

[5] Cooper CL, Watts J, Kelly M. Job satisfaction, mental health and job stressors among general dental practitioners in the UK. $\mathrm{Br}$ Dent J,162, 1987, 77-81.

[6] Garbee WH Jr, Zucker SB, Selby GR. Perceived sources of stress among dental students. J Am Dent Assoc,100, 1980,853-7.

[7] Kumar S, Dagli R, Mathur A, Jain M, Prabu D, Kulkarni S. Perceived sources of stress amongst Indian dental students. Eur J Dent Educ, 13, 2009, 39-45.

[8] Burk DT, Bender DJ. Use and perceived effectiveness of student support services in a first-year dental student population. $J$ Dent Educ,69(10), 2005,1148-60.

[9] Radcliffe C, Lester H. Perceived stress during undergraduate medical training: a qualitative study. Med Educ, 37, 2003,32-8.

[10] Dahlin M, Joneborg N, Runseson B. Stress and depression among medical students: a cross-sectional study. Med Educ, 39, 2005, 594-604.

[11] Sanders AE, Lushington K. Effect of perceived stress on student performance in dental school. J Dent Educ,66(1), 2002,75-81.

[12] Holm U, Aspergen K. Pedagogical methods and affect tolerance in medical students. Med Educ,33(1), 1999, 14-8.

[13] Pau AK, Croucher R. Emotional intelligence and perceived stress in dental undergraduates. J Dent Educ,67(9),2003,1023-8.

[14] Spencer J. Editorial: decline in empathy in medical education: how can we stop the rot? Med Educ,38, 2004,916-20.

[15] Acharya S. Factors affecting stress among Indian dental students. J Dent Educ,67(10), 2003,1140-8.

[16] Pohlmann K, Jonas I, Ruf S, Harzer W. Stress, burnout and health in the clinical period of dental education. Eur J Dent Educ, 9, 2005, 78-84.

[17] Ahmad M.S, Yusoff M., Razak I.A. Stress and its relief among undergraduate dental students in Malaysia. Southeast Asian J Trop Med Public Health , 42 (4), 2011, 996-1004 